\title{
Torres urbanas de la ciudad de Segovia. Un análisis de la silueta comparada
}

\author{
ANA M. ESCOBAR RODRÍGUEZ \\ Arquitecto / Junta de Castilla y León \\ escgonan@jcyl.es
}

\begin{abstract}
Resumen
Anton van den Wyngaerde, paisajista flamenco del siglo XVI contratado por Felipe II, nos ofrece en el año 1562 dos grabados de la ciudad de Segovia. En ellos representa una doble silueta de la ciudad, una corresponde a la cornisa norte y la otra a la cornisa sur. Presento un análisis de la silueta de la ciudad de Segovia vista por los grabados, las litografías y las fotografías antiguas, que forman parte del documento gráfico de la historia de la ciudad, comparando estos grabados y fotografías históricas con las imágenes realizadas en la actualidad. Son numerosos los artistas que nos han dejado un legado de imágenes realizadas desde los parajes exteriores, entre otros: Louis Meunier c.a. 1666, Day-Haghe 1838, Bichebois-Bayot 1844, Guesdon 1854, J. Laurent 1868-1872, Mariano Moreno 1900, Alois Beer 1906, Loty 1932-1936.

Los elementos de mayor repercusión en la silueta de la ciudad son la Catedral, el Acueducto y el Alcázar, pero además de estas tres edificaciones presto una especial atención a las torres urbanas que pertenecen a los campanarios de las Iglesias y a las torres de la arquitectura civil que pertenecen a las residencias urbanas que fueron construidas por las familias nobles, buscando y reconociendo su silueta en la ciudad. Después de analizar el paisaje urbano que se observa desde los miradores exteriores de la ciudad, propongo subir a lo alto de alguna de estas torres para tener la oportunidad de contemplar las visuales cruzadas que se producen entre ellas, para comparar las transformaciones y las permanencias de la ciudad amurallada y de su entorno.
\end{abstract}

Palabras clave: Silueta urbana; torres; paisaje urbano. 


\title{
Urban towers in the city of Segovia. Comparative analysis of skyline
}

\begin{abstract}
Anton van den Wyngaerde was a sixteenth century Flemish landscape who was contracted by Philip II. In the year of 1562 he painted two prints of the city of Segovia. These prints displayed the skyline north and south of the city.

This work about the analysis of the Segovia's skyline compares engravings, lithographs and old photographs, all of them documents of the city's history, with actual engravings and photographs. Many artists have left images taken from outdoor landscapes, including: Louis Meunier c.a. 1666, Day-Haghe 1838, Bichebois-Bayot 1844, Guesdon 1854, J. Laurent 1868-1872, Mariano Moreno 1900, Alois Beer 1906, Loty 1932-1936.

Most prominent elements in the skyline of the city are the Cathedral, the Aqueduct and the Alcazar, but also require special attention urban towers of church steeples and towers of civil architecture built by noble families to reside there. Finally I propose to climb to the top of one of these towers to have the opportunity to see the visual effects that occur between them, and compare the transformations and original walled city and its surround-dings.
\end{abstract}

Key words: Urban skyline; tower; urban landscape.

Sumario: 1.- Objeto. 2.- Silueta urbana. 3.- Fuentes gráficas de la ciudad de Segovia. 3.1.- Grabados y Litografías 3.2.- Fotografías históricas 4.- Análisis de la silueta urbana. 4.1.- Elementos destacables en la silueta 4.2.- Tipos de Torres Urbanas 4.3.- Visuales cruzadas 4.4.- Silueta comparada 5.- Identificación de los valores de la silueta urbana. 6.- Referencias bibliográficas. 


\section{Objeto.}

Al dibujar nuestras viejas ciudades, pueblos y castillos, y al recorrer los campos de nuestra geografía, hemos ido viendo, su importancia en el paisaje, y el valor de la propia ciudad como paisaje (Cano Lasso, 1985: 7).

El objeto de esta comunicación presentada en las Jornadas Internacionales de Arte y Ciudad, es el análisis de la silueta urbana de la ciudad de Segovia, contemplada desde los miradores exteriores de la ciudad que nos permite su particular situación topográfica, teniendo como principal elemento de estudio las Torres Urbanas de distinta naturaleza arquitectónica. Siguiendo un proceso en varias fases: Comenzar por la observación y la descripción de la silueta urbana; después seleccionar las fuentes gráficas formadas por grabados y fotografías históricas; para continuar con el análisis de la silueta urbana; y por último concluir con la identificación de los valores de transformación y permanencia, estableciendo un sistema para comprender el significado de la ciudad.

\section{Silueta urbana.}

La silueta urbana de una ciudad se crea cuando se tiene la posibilidad de contemplar su perfil desde el exterior y a una distancia adecuada que permita recortar su silueta sobre el cielo. La ciudad en su silueta se entiende necesariamente vinculada al paisaje urbano y al territorio sobre el que se asienta, crece y se transforma.

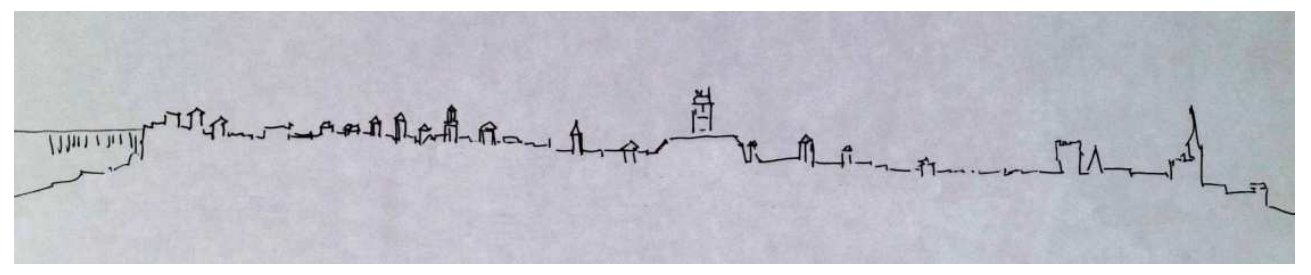

Fig. 1. Silueta de la ciudad de Segovia destacando sus torres.

La ciudad amurallada de Segovia se encuentra situada entre las cuencas de los ríos Eresma y Clamores, esto le permite tener unas visuales exteriores para contemplar su silueta desde distintos emplazamientos. A lo largo de los siglos ha sido representada en grabados y fotografías por numerosos artistas que nos han dejado un legado de imágenes realizadas desde los distintos parajes. 
La relación entre la ciudad y el paisaje urbano la describe Miguel Aguiló en El paisaje construido, expresándolo como una indagación sobre la necesidad esencial del hombre, que es construir, como forma humana de transformar el territorio que ocupa, planteando que las ciudades son dinámicas y se transforman en un continuo sucederse del tiempo:

Los sitios son entidades dinámicas. El paso del tiempo produce nuevas actividades y significados que se van acumulando a los existentes y modifican las características del sitio lugar (Aguiló, 1999: 278).

Para el caso concreto de Segovia, José Luis García Fernández publicó en el año 1982: Segovia en el paisaje, un interesante recorrido paisajístico de aproximación a la ciudad de Segovia, a través de una amplia colección de dibujos y descripciones de su silueta desde distintos puntos de vista. Dibujando imágenes paisajísticas analizadas desde distintos lugares y a diferentes distancias, en una aproximación continúa que denomina: horizonte lejano, horizonte medio, horizonte próximo, horizonte inmediato y horizonte cero.

Otra referencia destacable es Julio Cano Lasso, que realizó en el año 1985, un análisis de varias ciudades españolas, entre ellas Segovia, dibujando las ciudades fundidas en el paisaje, publicado en: La ciudad y su Paisaje. En ella describe como la incorporación al paisaje se produce de manera natural y que el paso del tiempo va fundiendo arquitectura y naturaleza en el mismo color y materia.

El paso de tantas gentes distintas con su continuo hacer y deshacer, ha configurado lentamente la ciudad y elaborado una rica amalgama de estilos. Así Geografía, Arquitectura y Arte, se funden a lo largo de la historia y nos ponen en comunicación con el pasado, del que provienen nuestras raíces (Cano Lasso, 1985: 7).

En las páginas dedicadas a Segovia, Julio Cano Laso, destaca entre otras reflexiones, la que corresponde con el territorio que circunda la ciudad, expresando lo siguiente:

el paisaje que rodea Segovia se caracteriza por tres elementos: la sierra del Guadarrama, con sus estribaciones y pinares; las onduladas tierras de labor, y los numerosos ríos que bajan de la nieve próxima y que corren entre arboledas por valles profundos. La sierra pone un fondo azul a los dorados o pardos campos de labor, que hacia el norte se pierden en la llanura de Castilla (Cano Lasso, 1985:115). 
Lo anteriormente expuesto nos viene a recordar que la silueta de cada ciudad está directamente vinculada al territorio donde se asienta, formando un paisaje singular y diferenciado de todas las demás.

\section{Fuentes gráficas de la ciudad de Segovia.}

Son numerosos los artistas y viajeros que han recogido en su obra gráfica la ciudad de Segovia; disponemos de grabados, litografías y fotografías que componen un Archivo Gráfico de interés para poder analizar las transformaciones de la silueta de la ciudad. Selecciono algunas de estas imágenes, en las que se contempla una visión completa del perfil de la ciudad, diferenciado en dos apartados, uno dedicado a los grabados y litografías y otro dedicado a las fotografías históricas

\subsection{Grabados y Litografías.}

Comienzo por los grabados de Anton Van den Wyngaerde, paisajista flamenco del siglo XVI, contratado por Felipe II, que nos ofrece en el año 1562 dos grabados de la ciudad. En ellos representa una doble representación de la ciudad, correspondientes a la cornisa norte y a la cornisa sur. Publicados junto a los grabados de otras ciudades españolas en: Ciudades del siglo de Oro. Las vistas españolas de Anton Van den Wyngaerde, dirigido por Richard L. Kagan en el año 1986. En los dos grabados se pueden observar el Alcázar y el Acueducto en los extremos de la ciudad amurallada, también se observan la Catedral nueva y de la torre de San Esteban que aparecen como hitos destacables de la silueta. En el esquema siguiente de la ciudad amurallada y las colinas del entorno se señalan los lugares aproximados desde donde están realizados los dos grabados de Anton Van den Wyngaerde.

Para su localización se ha realizado un recorrido por la cornisa que bordea la ciudad al otro lado de los valles del Eresma y del Clamores, buscando la misma relación entre las arquitecturas más significativas que tienen en los grabados una mayor relevancia y que son reconocibles en su silueta actual. Para localizar el lugar de realización del grabado de la cornisa norte, se ha recorrido la cornisa, siguiendo el paraje de Las Lastras, buscando la franja de movimiento desde la que se puede ver el Alcázar y el Acueducto en una misma visual, para después concretar el lugar con la ubicación similar a la del 
grabado de la Catedral y la torre de San Esteban. Para localizar el lugar del grabado de la cornisa sur, se ha seguido el mismo proceso, recorriendo la cornisa sur y trabajando sobre el plano con el ángulo de visión, por la dificultad que supone la plantación de los árboles del Pinarillo, que impide actualmente tener una visión conjunta del Alcázar y del Acueducto.

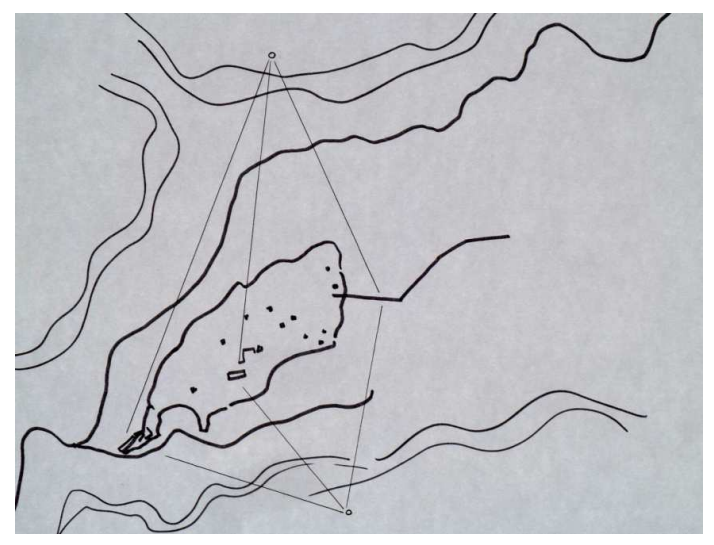

Fig. 2. Esquema de la ciudad y su entorno donde se señalan los lugares aproximados desde donde están realizados los dos grabados de Anton Van den Wyngaerde.

Otros grabadores nos han dejado un legado de imágenes realizadas desde los parajes exteriores. Un ejemplo de ellas lo encontramos en la publicación: Imágenes de Segovia en las Artes de la Estampa, que recoge parte de la amplia y extensa colección de grabados, litografías y aguafuertes que componen la colección de Caja Segovia, recogidas en el catálogo de la exposición que se realizó en el año 2004, siendo el Comisario de la misma Juan Manuel Santamaría. Selecciono tres grabados por ser las representaciones exteriores que mejor captan el paisaje urbano y la silueta de la ciudad:

- Profil de la ville de Segovie, de Louis Meunier c.a. 1666. Una talla dulce de pequeño tamaño 55.7 x $24.3 \mathrm{~cm}$ (Santamaría, 2004:68), en la que representa la silueta de la ciudad en el siglo XVII, destacando la Catedral situada en lo más alto y representando una ciudad cuajada de torres que resaltan en la silueta de la ciudad.

- Segovia, dibujo de G. Vivian, litografía de Day y L. Haghe. 1838. Otra representación de pequeño tamaño 24 x $38.5 \mathrm{~cm}$ (Santamaría, 2004: 81), en la que se representa la ladera norte con la silueta de la ciudad, destacando el Alcázar, la Catedral, la torre de San Esteban y la muralla con la puerta de Santiago. 
- Vista de Segovia desde la ermita de Zamarramala, litografía de Guesdon. 1854. Tamaño $44 \times 26.8 \mathrm{~cm}$ (Santamaría, 2004:83). En la que se descubre una primera escena costumbrista, con la ciudad al fondo enmarcada por el Alcázar y los monasterios situados a orillas del río Eresma. Se descubren en el interior de la ciudad varias torres urbanas, entre otras el torreón Arias Dávila, escoltadas entre la Catedral y la torre de San Esteban.

\section{2. Fotografías históricas.}

Un apartado diferente es el formado por las distintas colecciones de fotografías de la ciudad. Fotógrafos como J. Laurent 1868-1872, Mariano Moreno 1900, Alois Beer 1906, Loty 1932-1936 han recogido interesantes imágenes de la ciudad. Pertenecientes a distintas colecciones públicas y privadas consultadas a través de las publicaciones que recientemente se han realizado.

El Instituto de Patrimonio del Ministerio de Cultura y la Fundación Mapfre, han publicado en el año 2006, un recopilatorio sobre las fuentes fotográficas del Patrimonio Cultura de Segovia, seleccionando las fotografías de tres colecciones que pertenecen al propio Instituto de Patrimonio, Laurent, Moreno y Loty. A continuación relaciono algunas de estas fotografías por su interés histórico y paisajístico, con una descripción y una referencia para su localización que han servido para elaborar la comparativa de la silueta urbana.

- Segovia. Vista general desde las nieves, Jean Laurent entre 1868 y 1872. Negativo de vidrio al colodión, formato $27 \times 36 \mathrm{~cm}$. Archivo Ruiz Vernacci. № de inventario VN-03561. Fototeca del Instituto del Patrimonio Histórico Español (IPHE) (VV.AA., 2006: 59). Imagen de la ladera norte a finales del siglo XIX, vista del valle del Eresma en primer plano y la ciudad amurallada presidida por la Catedral y el Antiguo Convento de los Agustinos antes de su derribo parcial, las torres de San Esteban, San Andrés, San Martin y Torreón Arias Dávila.

- Segovia. Vista tomada desde la Piedad, Mariano Moreno c.a. 1900. Negativo de vidrio a la gelatina de plata, formato $24 \times 30 \mathrm{~cm}$. Archivo Moreno. № inventario 0040-C. Fototeca del IPHE. (VV.AA., 2006:88). Arrabal de San Millán, muralla y varias torres de la ciudad, iglesia de San Martin, las dos torres del Lozoya, Seminario y el Acueducto. 
- Segovia. Vista tomada desde las nieves, Mariano Moreno c.a. 1900. Negativo de vidrio a la gelatina de plata, formato $24 \times 30 \mathrm{~cm}$. Archivo Moreno. № de inventario 0039-C. Fototeca IPHE. (VV.AA., 2006: 89). Desde el este de la ciudad con el Acueducto, la torre de San Justo, la muralla, el edificio del Seminario, San Sebastián y la Casa de las Cadenas.

Otra fuente gráfica documental es la amplia colección de fotografías de la ciudad de Segovia que el fotógrafo austro-húngaro, Alois Beer, nacido en Budapest 1840-Klagenfurt 1916, realizó en su visita a la ciudad en el año 1906, y que se publicó en Leizzig en el año 1913, en la guía turística Segovia, Avila und El Eskorial que el historiador y viajero August L. Mayer realizó después de su viaje por España. Estas fotografías se han vuelto a publicar recientemente por el Ayuntamiento de Segovia y el Instituto Histórico Austriaco en el año 2004: Segovia hace 100 años. "Como una coqueta con un velo", refiriéndose al filtro que supone la construcción del acueducto comunicando los dos extremos de la vaguada. De la amplia colección de fotografías realizadas selecciono las dos panorámicas que mejor permiten observar la silueta de las torres. Una de ellas realizada desde la plaza de San Millán y la otra desde lo alto del Acueducto.

- Vista de la Iglesia de San Millán con el Acueducto al fondo. Alois Beer. 1906 (Rudolf, 2004:104). La iglesia de San Millán en un primer plano y se observa al fondo la ciudad amurallada con la fachada de Casa de los Picos.

- Vista desde lo alto de Acueducto hacia los restos de la Iglesia de Santa Columba, la calle cervantes y al fondo la catedral. Alois Beer. 1906. (Rudolf, 2004:52). Un punto de vista singular por encontrarse sobre el Acueducto en su parte más alta, permite ver una imagen singular de la ciudad con los arrabales extramuros en un primer plano y la muralla que encierra y protege la parte alta con sus torres de defensa.

Otra fuente gráfica es la colección Sáez-Laguna. Con la conmemoración del 125 aniversario de la declaración del Acueducto como monumento nacional, el Ayuntamiento de Segovia, publica en el año 2009: El Acueducto en fotografía. Recoge muchas escenas urbanas que tienen como telón de fondo el Acueducto. He seleccionado dos fotografías panorámicas muy interesantes, por permitir tener una visión completa de la ciudad en dos momentos históricos diferentes, vista desde la parte sur de la ciudad. La separación en años 
entre las dos fotografías nos permite observar la transformación de la ladera sur, las nuevas construcciones y la permanencia de los elementos más significativos de la silueta urbana.

- Una vista panorámica c.a. 1870 de la sociedad artística de fotografía, colección Sáez-Laguna.

- Panorama desde la Piedad, de Río c.a. 1953, colección Sáez-Laguna.

\section{Análisis de la silueta urbana.}

\subsection{Elementos destacables en la silueta.}

Observando la fotografía de la ciudad de Segovia destacan los elementos que configuran su silueta urbana. Una parte del aspecto actual de la ciudad alta, viene heredada de la ciudad medieval, las parroquias, viviendas populares, residencias de nobles, casas torre para la defensa de la ciudad, la muralla y el Alcázar. Hay tres construcciones que destacan por su mayor significación topográfica, simbólica y arquitectónica, que son: El Acueducto romano, como construcción perteneciente a la antigüedad que cruzando la vaguada abasteció de agua a la ciudad situada en la parte alta; en el extremo contrario se encuentra El Alcázar, como fortaleza en distintos momentos de la historia, situado en una cota topográfica inferior cercano a la confluencia entre los ríos Eresma y Clamores; y la Catedral nueva situada en la zona topográfica más elevada de la ciudad que destaca por su volumen del resto de las edificaciones, construida a partir del siglo XVI.

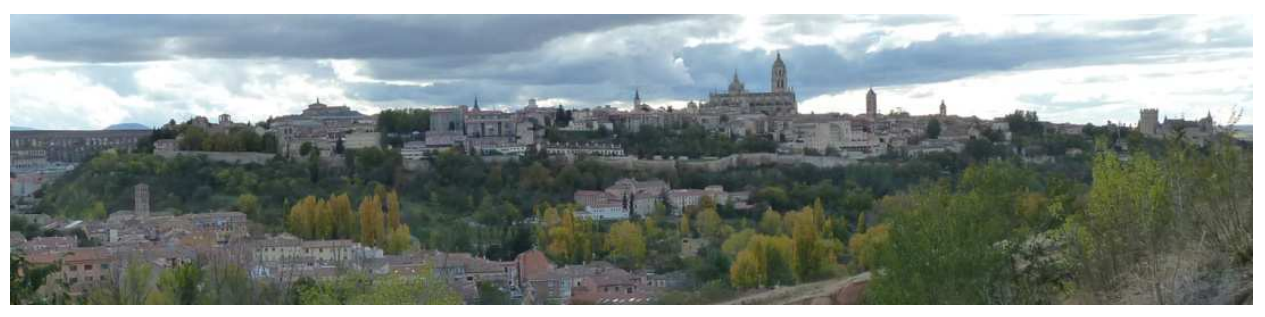

Fig. 3. Fotografía de la ladera norte de la ciudad de Segovia.

Otro de los elementos que conforman la silueta de la ciudad es la muralla que cierra el perímetro de la ciudad alta y que aparece representada como elemento que separa y distingue el interior de la ciudad alta de los arrabales 
que se extienden formando la ciudad baja. También tienen una relevancia importante en la silueta, las torres urbanas que pertenecen a los campanarios de las Iglesias y las torres de la arquitectura civil de las residencias urbanas que fueron construidas por las familias nobles, buscando y reconociendo la silueta de la ciudad.

Por último, se reconocen en la silueta las construcciones realizadas en el Edad Moderna y la Edad Contemporánea, sobre todo los grandes edificios que han ido transformando la silueta representada en los grabado de Anton van Wyngaerde. Desde el edificio del Seminario o el Antiguo convento de San Agustín construidos a partir de la segunda mitad del siglo XVI; a las viviendas y edificaciones del siglo $\mathrm{XX}$, como son el grupo de viviendas del Taray, el hotel sirenas en el borde sur, que forman parte de la actual y transformada silueta urbana de la ciudad.

\subsection{Tipos de torres urbanas.}

Las Torres Urbanas de la ciudad son el elemento arquitectónico que ha dado título a este análisis urbano, destacando en la silueta, como símbolo de permanencia que ha superando el paso del tiempo. Los propietarios y maestros de obra que construyeron estas torres, tenían que sentirse conocedores de realizar una obra perteneciente a una categoría diferenciada que transciende del hecho mismo de su propia construcción. Las torres de la ciudad, aun teniendo una significación propia cada una de ellas, se pueden agrupar en la siguiente clasificación ordenada por la repercusión que refleja su silueta.

- Torre de la Catedral. Se eleva como el elemento de superior altura sobre la silueta de la ciudad.

- Torres del Alcázar. El Alcázar se encuentra situado en el extremo de la ciudad a una cota inferior, pero con una silueta de singularidad y trascendencia reseñables.

- Torre de campanario de iglesia. Se incluyen todas las que pertenecen a las numerosas parroquias de la ciudad: San Esteban, San Andrés, San Miguel, San Martín, San Juan, San Sebastián, entre otras.

- Torres perteneciente a la arquitectura civil. Esta categoría agrupa las torres que pertenecen a la arquitectura civil mandadas construir por las 
familias nobles de la ciudad, con una doble finalidad, la residencial y la defensiva, se pueden clasificar en distintas categorías:

- Torre perteneciente a una casa fuerte. De las torres vinculadas a las puertas de acceso a la ciudad, la más destacable es la Casa de las Cadenas, situada sobre la muralla junto a la desaparecida puerta de San Juan. Otra casa fuerte es la Casa de los Picos, unida a la desaparecida puerta de San Martín, tiene una torre actualmente perteneciente al Seminario que fue de la casa fuerte que defendía el recinto amurallado. Otras edificaciones reconocidas como casa fuerte se encuentran en la actual plaza del platero Oquendo, dos torreones unidos a los edificios respectivos que elevan una planta sobre el resto de la estructura arquitectónica.

- Torreón singular. Tiene una mayor altura que rivaliza en la silueta urbana con los campanarios de las iglesias. Son tres los torreones singulares que se encuentran en la estructura urbana de la ciudad amurallada, son el Torreón de Lozoya, el Torreón de Hércules, el Torreón Arias Dávila.

- Otras Torres. Casa-torre que también se vinculan a una estructura de casa nobiliaria, pero que resultan menos perceptibles en la silueta, como es la Casa de los Rueda.

\subsection{Visuales cruzadas.}

Sobre el caserío del recinto amurallado destaca la silueta de los hitos arquitectónicos que superan en altura al resto de las construcciones. A lo largo del análisis hemos observado que son las torres las que determinan la silueta de la ciudad, la topografía acentúa la dimensión de algunas de ellas. Tenemos la posibilidad de observar las edificaciones de mayor altura ascendiendo a lo alto de alguna de ellas, desde donde se comprueba un cruce de visuales muy interesante, sabiéndose visto y vigilados desde la distancia.

Comenzamos subiendo a lo alto de La Catedral, desde allí se observa una imagen de cubiertas de la ciudad salpicada por la torres de las iglesias y los torreones de la arquitectura civil, al fondo se observa el trazado del Acueducto.

Desde lo alto del Torreón de Hércules, mirando hacia el norte se descubren dos de los hitos de la ciudad, como son la torre de San Esteban y a lo lejos la torre de Juan II del Alcázar. Asomándonos por otra de las ventanas que 
miran hacia el sur descubrimos el Torreón de los Arias Dávila, rivalizando en altura y desafío constructivo.

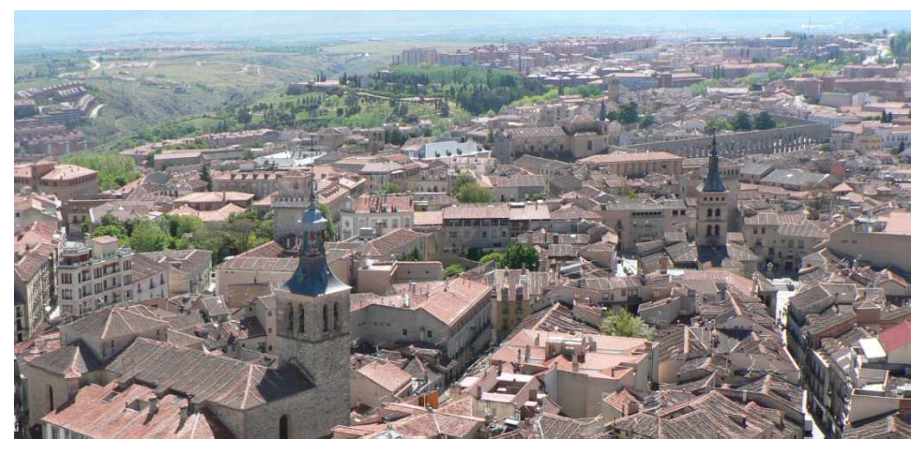

Fig. 4. Fotografía realizada desde lo alto de la catedral

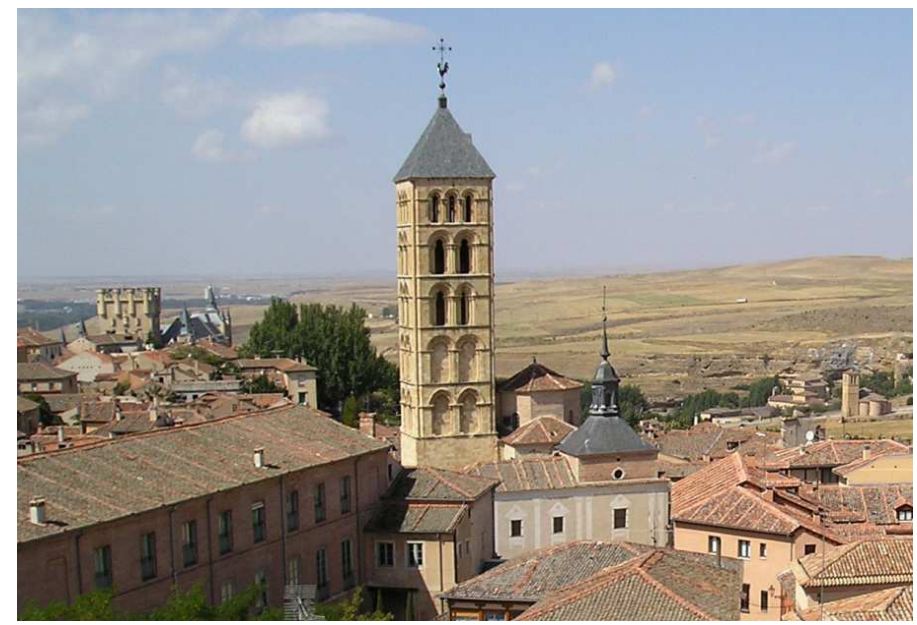

Fig. 5. Fotografía realizada desde la Torreón de Hércules

Desde las ventanas de la Torre de la casa de los Cascales-Barros situada en la plaza platero Oquendo se tiene una visual cruzada con el torreón de Lozoya, que da un valor de vigilancia mutua entre las arquitecturas nobiliarias de la ciudad.

Finalmente, desde otros muchos lugares de la ciudad que superan las cubiertas de los edificios cercanos, se tiene una visual cruzada con los hitos que representan los Torres más altas de la ciudad, junto a los campanarios de las Iglesias, que nos revelan la permanencia en el tiempo de estas arquitecturas históricas. 
Fig. 6. Fotografía realizada desde la Torre de la Casa Cascales Barros

Fig. 7. Fotografía realizada por encima de las cubiertas que permite disfrutar de la silueta urbana de las torres.
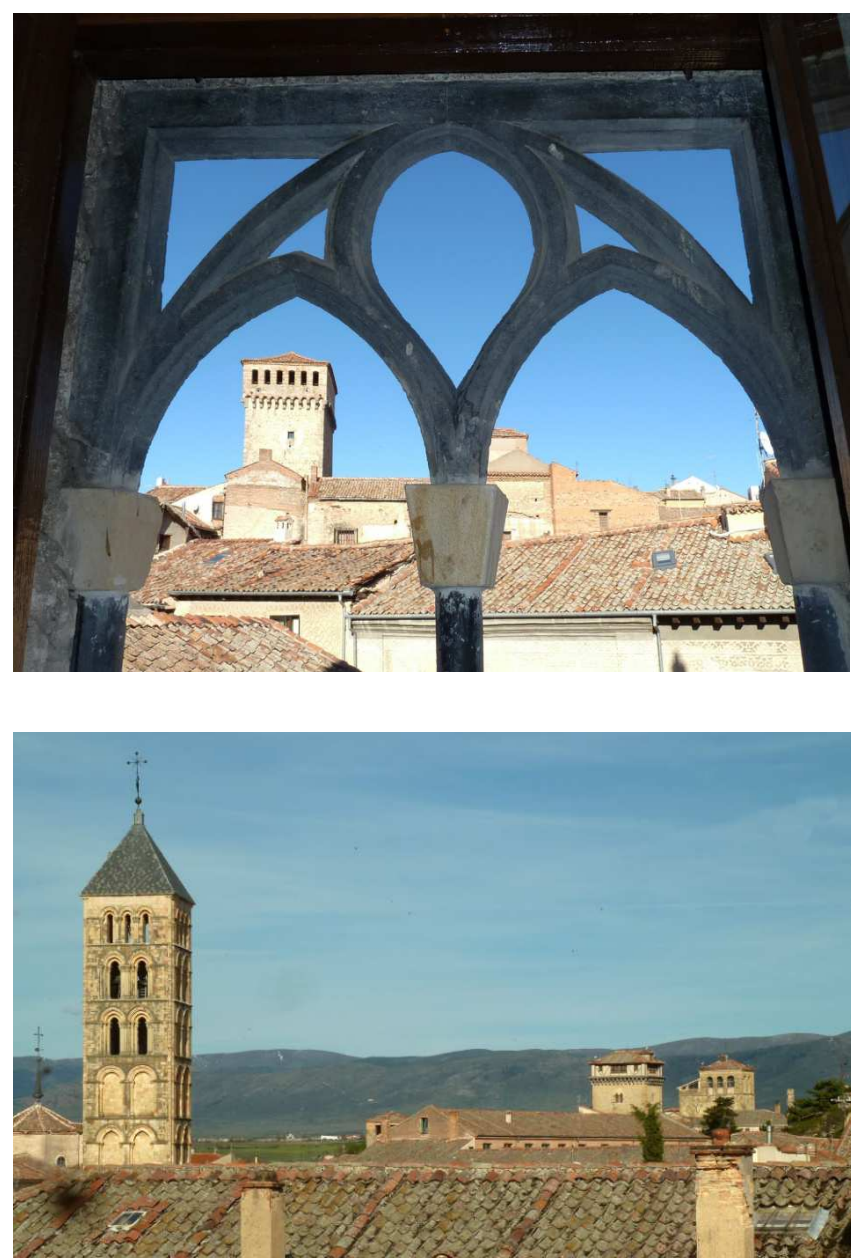

\subsection{Silueta comparada.}

En este apartado presento una comparativa entre las imágenes de la documentación gráfica histórica y la fotografía de la situación actual, comprobando la permanencia de algunos elementos, así como la aparición y transformación de otros. Para el análisis de la silueta comparada elijo dos lugares de diferente significado, como son los Altos de la Piedad y la vista de la ciudad desde la Torre del Alcázar.

Desde los Altos de la Piedad se tiene una visión completa del exterior de la ciudad desde la cornisa sur, son muchos los grabados y fotografías que tene- 
mos para poder comparar y analizar la silueta de la ciudad, en la actualidad todavía se perfila una silueta de las torres de construcción medieval que han marcado la silueta de la ciudad, la muralla delimita la ciudad alta.

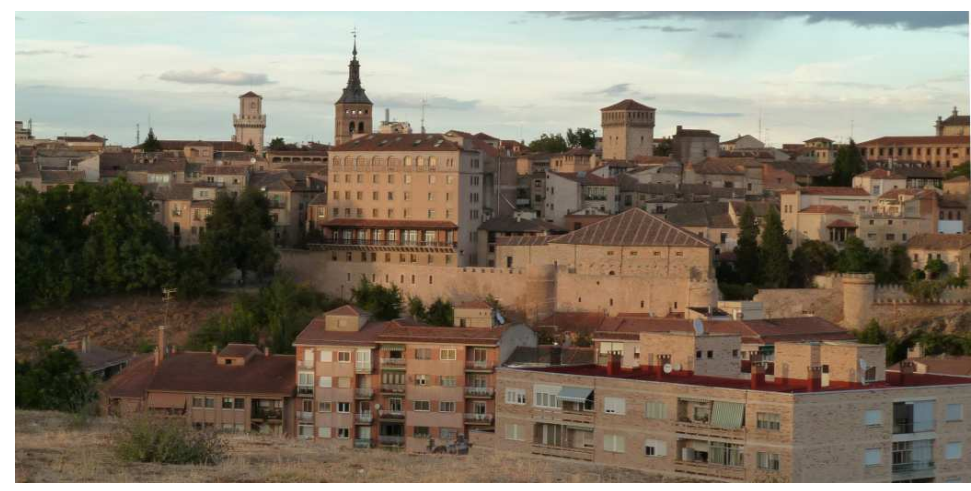

Fig. 8. Panorámica de la ciudad de Segovia desde los Altos de la Piedad.

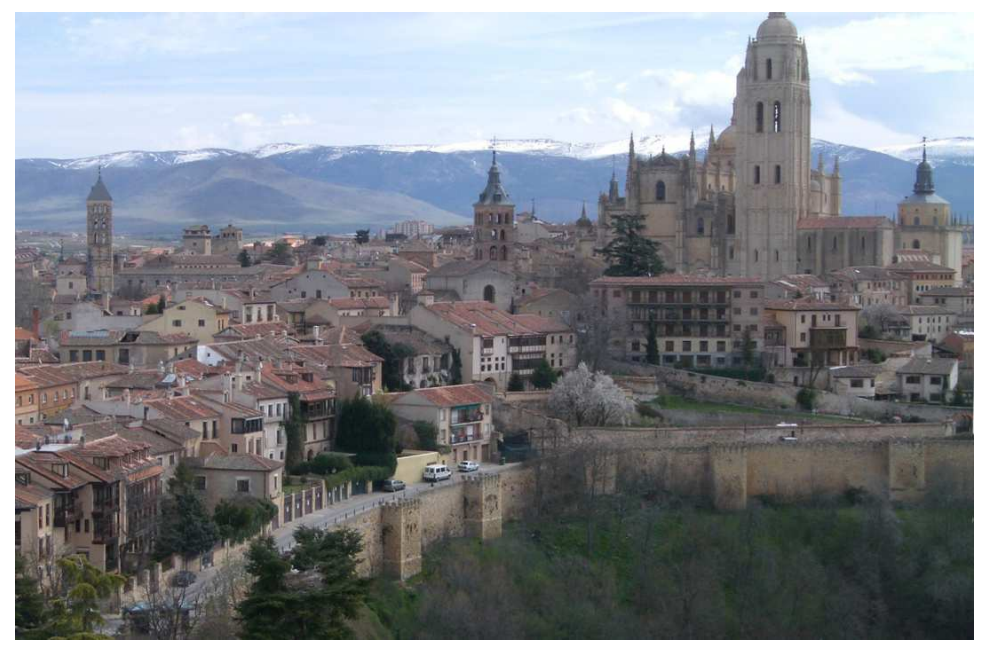

Fig. 9. Panorámica de la ciudad de Segovia desde la torre del Alcázar.

Actualmente desde los Altos de la Piedad, se comprueba que la silueta de los torreones se ha mantenido, aunque algunos grandes edificios como el hotel sirenas y el edificio del Seminario se han apoderado de parte de la silueta. La muralla aparece delimitando la parte baja del recinto de la ciudad alta, siguiendo un trazado según la topografía de la ladera sur. Los dos torres del Lozoya se reconocen en las dos fotografías y a un nivel inferior se descubre también la torre de la muralla junto a la Casa de los Picos, incluso se encuentra en la parte inferior en el extremo derecho el Acueducto. 
Un aspecto diferente nos muestra la fotografía actual desde la torre de Juan II en el Alcázar, que tiene la misma silueta que Loty fotografió entre 1932-1936 (NIM 02271. Fototeca IPCE). En la vista parcial se reconocen las torres de Hércules y de la Iglesia de la Trinidad, escoltadas por las Torres de San Esteban, San Martín y la Catedral, reflejando una permanencia de la silueta urbana.

\section{Identificación de los valores de la silueta urbana.}

A modo de conclusión, establecemos la identificación de los valores como sistema para comprender el significado de la silueta urbana. Juan Pablo Bonta en: Sistemas de significación en arquitectura, analiza la arquitectura como objeto material y como realidad cultural, buscando los sistemas de significación que permitan clasificar los indicadores y las variables. Sabiéndose conocedor de la dificultad que confiere esta búsqueda y reflexionando que los sistemas de significación en arquitectura y arte se encuentran en permanente estado de transformación y adaptación (Bonta, 1977:42). Llegando a exponer que: lo que la gente quiere es leer sus propios significados en el entorno de significados construidos a partir de un sistema de valores, con su propio marco de referencia (Bonta, 1977: 252).

A continuación propongo un sistema de valores que permita establecer un sistema de significación para comprender y valorar la silueta urbana. Realizando un recorrido de aproximación desde distintas referencias que se agrupan en el análisis global:

- Valor del lugar. La geografía y la topografía elegida marcan el punto de partida. La localización de la ciudad sobre la colina entre dos ríos permite destacar la silueta de sus torres.

- Valor paisajístico. Considerando el entorno como parte del conjunto urbano que compone su silueta. Las visuales cruzadas permiten tener una visión del paisaje intercambiable.

- Valor histórico. La silueta urbana agrupa y superpone en su perfil los acontecimientos y las construcciones que marcan el paso de la historia reflejada en sus distintas arquitecturas.

- Valor de transformación. A lo largo del tiempo se producen variaciones en la construcción y sustitución de edificios, así como en la expansión de la ciudad para adaptarse a las nuevas solicitudes 
- Valor de uso. La utilidad, utilitas, como uno de los tres paradigmas de la historia de la arquitectura, provoca cambios en su adaptación a los nuevos usos.

- Valor de permanencia. Por último el valor más reseñable por su valor de símbolo en el tiempo, de pervivencia entre las vicisitudes de la historia de la ciudad, sus transformaciones, adaptaciones a los nuevos usos, todo queda vinculado desde su origen.

\section{Bibliografía.}

AguILÓ, M. (1999): El paisaje construido. Una aproximación a la idea de lugar, Colegio de Ingenieros de Caminos, Canales y Puertos, Madrid.

BALleSter, J. M. -pro- (2009): Colección Sáez-Laguna. El acueducto en la fotografía, Ayuntamiento de Segovia, Segovia.

BONTA, J. P. (1977): Sistemas de significación en arquitectura, Gustavo Gili, Barcelona.

CANO LASSO, J. (1985): La ciudad y su paisaje, Edición del autor, AG. Grupo, S.A., Madrid.

Chaves MArTín, M. A. (1998): Catálogo Guía de arquitectura de Segovia, Obra social y cultural de Caja Segovia, Segovia.

GARCÍA FERNÁNDEZ, J. L. (1982): Segovia en el paisaje, Ediciones de Librería Estudio, Santander.

KAGAN, R. L. - dir- (1996): Ciudades del siglo de oro. Las vistas españolas de Anton Van den Wyngaerde, El Viso, Madrid.

SANTAmaría, J. M. (2004): Imágenes de Segovia en las Artes de la Estampa. Caja Segovia obra social y cultural, Segovia.

Rudolf, K. F. -dir- (2004): Segovia hace 100 años. "Como una coqueta con un velo", Ayuntamiento Segovia-Instituto Histórico Austriaco, Madrid.

VV.AA. (2006): Segovia en tres tiempos. Fotografías de Laurent, M. Moreno, Loty. 1856-1939, Fundación MAPFRE- Instituto de Patrimonio Histórico Español, Madrid. 